\title{
Alcohol and Breast Cancer in Women
}

\section{A Pooled Analysis of Cohort Studies}

\author{
Stephanie A. Smith-Warner, PhD; Donna Spiegelman, ScD; Shiaw-Shyuan Yaun, MPH; \\ Piet A. van den Brandt, PhD; Aaron R. Folsom, MD; R. Alexandra Goldbohm, PhD; \\ Saxon Graham, PhD; Lars Holmberg, MD, PhD; Geoffrey R. Howe, PhD; \\ James R. Marshall, PhD; Anthony B. Miller, MB, BCh; John D. Potter, MB, BS, PhD; \\ Frank E. Speizer, MD; Walter C. Willett, MD; Alicja Wolk, DMSc; David J. Hunter, MB, BS
}

Objective.--To assess the risk of invasive breast cancer associated with total and beverage-specific alcohol consumption and to evaluate whether dietary and nondietary factors modify the association.

Data Sources.-We included in these analyses 6 prospective studies that had at least 200 incident breast cancer cases, assessed long-term intake of food and nutrients, and used a validated diet assessment instrument. The studies were conducted in Canada, the Netherlands, Sweden, and the United States. Alcohol intake was estimated by food frequency questionnaires in each study. The studies included a total of 322647 women evaluated for up to 11 years, including 4335 participants with a diagnosis of incident invasive breast cancer.

Data Extraction.-Pooled analysis of primary data using analyses consistent with each study's original design and the random-effects model for the overall pooled analyses.

Data Synthesis._For alcohol intakes less than $60 \mathrm{~g} / \mathrm{d}$ (reported by $>99 \%$ of participants), risk increased linearly with increasing intake; the pooled multivariate relative risk for an increment of $10 \mathrm{~g} / \mathrm{d}$ of alcohol (about 0.75-1 drink) was 1.09 (95\% confidence interval [Cl], 1.04-1.13; $P$ for heterogeneity among studies, .71). The multivariate-adjusted relative risk for total alcohol intakes of 30 to less than $60 \mathrm{~g} / \mathrm{d}$ (about 2-5 drinks) vs nondrinkers was 1.41 (95\% Cl, 1.18-1.69). Limited data suggested that alcohol intakes of at least $60 \mathrm{~g} / \mathrm{d}$ were not associated with further increased risk. The specific type of alcoholic beverage did not strongly influence risk estimates. The association between alcohol intake and breast cancer was not modified by other factors.

Conclusions.-Alcohol consumption is associated with a linear increase in breast cancer incidence in women over the range of consumption reported by most women. Among women who consume alcohol regularly, reducing alcohol consumption is a potential means to reduce breast cancer risk.

JAMA. 1998;279:535-540

From the Departments of Nutrition (Drs SmithWarner and Willett), Epidemiology (Drs Spiegelman, Willett, and Hunter), Biostatistics (Dr Spiegelman), and Environmental Health (Dr Speizer), Harvard School of Public Health, Boston, Mass; Channing Laboratory, Department of Medicine, Brigham and Women's Hospital and Harvard Medical School, Boston (Ms Yaun and Drs Speizer, Willett, and Hunter); Department of Epidemiology, University of Maastricht, the Netherlands (Dr van den Brandt); Division of Epidemiology, School of Public Health, University of Minnesota, Minneapolis (Dr Folsom); Department of Epidemiology, TNO Nutrition and Food Research Institute, Zeist, the Netherlands (Dr Goldbohm); Department of Social and Preventive Medicine, State University of New York
ALCOHOL consumption is a potentially modifiable behavior that may influence the risk of breast cancer, a leading cause of morbidity and mortality in women. ${ }^{1}$ However, the relationship between alcohol intake and breast cancer risk is still controversial, even though over 50 epidemiologic studies have examined the association. ${ }^{2}$ Numerous studies have shown modest increases in risk associated with high alcohol consumption; however, many of these studies have been relatively small and the associations have not always been statistically significant. A recent meta-analysis ${ }^{2}$ found a monotonic increase in breast cancer risk with increasing alcohol consumption; however, statistically significant heterogeneity across studies was evident, raising doubts about whether the association is consistent in different study populations. Few studies have had sufficient numbers of cases to address the question of whether the association is similar for women in different subgroups defined by other breast cancer risk factors.

A limitation of meta-analyses is that the primary sources of data are published results in which alcohol intake has been analyzed using different analytic methods and cutoff points, thereby limiting the comparisons that can be made. In addition, the covariates included in regression models vary from study to study, resulting in differential control for confounding across studies. Analyses of factors that may modify the relationship between alcohol and breast cancer are also not possible from published data because few studies present these data in sufficient or comparable detail. The Pooling Project of Prospective Studies of Diet and Cancer was established to evaluate associations between 
Table 1.-Characteristics of the Cohort Studies Included in the Pooled Analysis of Alcohol and Breast Cancer

\begin{tabular}{|c|c|c|c|c|c|c|}
\hline Study & $\begin{array}{l}\text { Years of } \\
\text { Follow-up }\end{array}$ & $\begin{array}{l}\text { Baseline } \\
\text { Cohort }\end{array}$ & $\begin{array}{c}\text { Age } \\
\text { Range, } y\end{array}$ & $\begin{array}{l}\text { No. of } \\
\text { Cases* }\end{array}$ & $\begin{array}{c}\text { Mean (SD) } \\
\text { Alcohol } \\
\text { Intake, g/d†‡ }\end{array}$ & Nondrinkers, \%‡ \\
\hline $\begin{array}{l}\text { Canadian National Breast } \\
\text { Screening Study }\end{array}$ & $1982-1987$ & 56837 & $40-59$ & 419 & $12.58(17.58)$ & 23.3 \\
\hline Iowa Women's Health Study & 1986-1991 & 34406 & $55-69$ & 643 & $8.20(11.34)$ & 55.3 \\
\hline Netherlands Cohort Study & $1986-1989$ & 62412 & $55-69$ & 405 & $8.51(10.59)$ & 31.8 \\
\hline New York State Cohort & 1980-1987 & 18475 & $50-93$ & 367 & $5.47(8.48)$ & 22.5 \\
\hline Nurses' Health Study (a) & $1980-1986$ & 89046 & $34-59$ & 1023 & $10.14(13.07)$ & 32.5 \\
\hline Nurses' Health Study $(b)$ & 1986-1991 & 68817 & $40-65$ & 806 & $10.37(12.85)$ & 36.0 \\
\hline $\begin{array}{l}\text { Sweden Mammography } \\
\text { Cohort }\end{array}$ & $1987-1993$ & 61471 & $40-76$ & 672 & $3.22(3.02)$ & 37.6 \\
\hline Total & $\ldots$ & 322647 & $\ldots$ & 4335 & & \\
\hline
\end{tabular}

lifestyle factors and breast cancer risk in prospective studies using a standardized approach. This allowed us to build on previous meta-analyses of alcohol and breast cancer ${ }^{2,3}$ by including additional cohort studies, using uniform exposure categories and covariate definitions across studies, controlling for other dietary constituents, evaluating for effect modification, and correcting for measurement error in alcohol intake.

\section{METHODS}

The Pooling Project has been described previously. ${ }^{4,5}$ Briefly, 7 prospective studies ${ }^{6-12}$ (Table 1) were identified that met the following predefined criteria:(1) at least 200 incident breast cancer cases, (2) assessment of long-term intake of foods and nutrients, and (3) a validation study of the diet assessment method or a closely related instrument. Consequently, in addition to case-control studies, cohort studies that did not measure dietary data, did not assess long-term diet (ie, used 24-hour recall), did not validate their dietary assessment method, or were recently initiated were ineligible for these analyses. The Adventist Health Study also was excluded from these analyses since alcohol intake was negligible in this study. The Nurses' Health Study was divided into 2 studies (1980-1986 and 1986-1991 follow-up periods) since it had repeated assessments of dietary intake and a longer follow-up period than the other studies.

The baseline food frequency questionnaires for each study inquired about typical consumption of alcoholic beverages. For each beverage, daily alcohol intake in grams was calculated based on the frequency of consumption, the alcohol content of the beverage, and the average quantity consumed. Studyspecific conversion factors for the alcohol content of each beverage were used. Total alcohol intake was calculated as the sum of the beverage-specific intakes.
Risk factors for premenopausal and postmenopausal breast cancer may differ ${ }^{13-16}$; however, most studies had information on menopause status at baseline only. To assign changing menopause status during follow-up, an algorithm was developed based on an analysis of 42531 Nurses' Health Study participants who were premenopausal in 1976 and remained premenopausal or had natural menopause by 1992. Using KaplanMeier curves ${ }^{17}$ for time to menopause, we determined the ages at which approximately $50 \%$ (age 51 years) and $90 \%$ (age 55 years) of the women had become postmenopausal. These ages were used to define the upper and lower bounds for the premenopausal and postmenopausal categories, respectively, in the algorithm. The menopause status of women whose ages were between 51 and 55 years was considered uncertain.

Each study was analyzed using a method consistent with its study design. Five cohorts (Iowa Women's Health Study, New York State Cohort, Nurses' Health Study (a), Nurses' Health Study (b), and the Sweden Mammography Cohort) were analyzed as nested case-control studies with a 1:10 ratio of cases with diagnosed invasive breast cancer to controls free of diagnosed cancer. A nested case-control design also was used for the Canadian National Breast Screening Study; the investigators of that study selected 2 controls for each case. The Netherlands Cohort Study used a casecohort design. ${ }^{18}$

Participants were excluded from these analyses if they met study-specific exclusion criteria, reported energy intakes greater than 3 SDs from the studyspecific logarithm-transformed mean energy intake of the baseline population, reported a history of cancer except for nonmelanoma skin cancer at baseline, or had missing data on alcohol intake. For the 6 nested case-control studies, relative risks were estimated using conditional logistic regression (SAS PROC
PHREG $^{19}$ ); for the Netherlands Cohort Study, Epicure software was used. ${ }^{20} \mathrm{An}$ indicator variable for missing responses was created for each covariate. Twosided $95 \%$ confidence intervals (CIs) were calculated. The random-effects model developed by DerSimonian and Laird ${ }^{21}$ was used to combine logarithmic relative risks from the multiple studies. To calculate the $P$ value for trend, participants were assigned the median value of their category of total daily alcohol intake, and this variable was used as a continuous variable. We used the regression coefficients between alcohol intakes reported by food frequency questionnaires and by a reference method in the study-specific validation studies to deattenuate study-specific relative risks for measurement error in alcohol consumption (range of validity correlations, 0.33-0.86) (H. Ljung, MSc, A. Wolk, DMSc, D. Spiegelman, ScD, D. Hunter, MB, BS, for the Study Group of the Multiple Risk Survey on Swedish Women for Eating Assessment, unpublished results, 1995). ${ }^{22-26}$ The Canadian National Breast Screening Study was not included in the determination of the relative risks corrected for measurement errors because alcohol intake data were not available in the validation study.

We evaluated whether alcohol intake was linearly associated with breast cancer by comparing nonparametric regression curves using restricted cubic splines to the linear model using the likelihood ratio test, and by visual inspection of the restricted cubic spline graphs. ${ }^{27,28} \mathrm{Re}-$ stricted cubic splines are a graphical method of presenting dose-response curves that make no a priori assumptions about the shape of the curve. Cubic polynomials are fitted between prespecified knots, and restrictions are placed on the resulting curve to ensure a smooth appearance at these knot points. The studies were combined into a single data set stratified by study, since there was no between-study heterogeneity in the other model covariates ${ }^{5}$ and because alcohol intake was measured similarly in all studies. Four knot positions were specified at $1.5,5.0,15.0$, and $30.0 \mathrm{~g} / \mathrm{d}$ of alcohol. Other numbers and locations of knots were examined, and the curves were similar.

We evaluated whether several factors modified the alcohol and breast cancer association. For each factor of interest, an interaction term between alcohol intake expressed as a continuous variable and each level (excluding the referent level) of the factor was included in a standard multivariate model. Participants missing values for the factor of interest were excluded from these analyses. The 
Table 2.-Study-Specific and Pooled Multivariate Relative Risks* for Categories of Total Daily Alcohol Intake and Breast Cancer

\begin{tabular}{|c|c|c|c|c|c|c|c|c|}
\hline \multirow[b]{2}{*}{ Study } & \multicolumn{7}{|c|}{ Relative Risk (95\% Confidence Interval) by Total Daily Alcohol Intake, g/d†‡ } & \multirow[b]{2}{*}{$P$ (Trend) } \\
\hline & $\begin{array}{l}\text { Nondrinkers } \\
(n=1462)\end{array}$ & $\begin{array}{c}>0 \text { to }<1.5 \\
\quad(n=680)\end{array}$ & $\begin{array}{c}1.5 \text { to }<5.0 \\
(n=882)\end{array}$ & $\begin{array}{c}5.0 \text { to }<15.0 \\
(n=727)\end{array}$ & $\begin{array}{c}15.0 \text { to }<30.0 \\
(n=360)\end{array}$ & $\begin{array}{c}30.0 \text { to }<60.0 \\
(n=194)\end{array}$ & $\begin{array}{l}\geq 60.0 \\
(n=30)\end{array}$ & \\
\hline $\begin{array}{l}\text { Canadian National Breast } \\
\text { Screening Study }\end{array}$ & 1.0 & $1.29(0.84-1.97)$ & $1.08(0.73-1.59)$ & $0.94(0.64-1.37)$ & $1.39(0.90-2.13)$ & $1.89(1.02-3.49)$ & $0.96(0.37-2.50)$ & .23 \\
\hline $\begin{array}{l}\text { lowa Women's } \\
\text { Health Study }\end{array}$ & 1.0 & $0.98(0.74-1.30)$ & $1.00(0.78-1.27)$ & $0.97(0.73-1.29)$ & $1.37(0.94-1.98)$ & $1.74(1.12-2.70)$ & $1.74(0.49-6.15)$ & .007 \\
\hline $\begin{array}{l}\text { Netherlands Cohort } \\
\text { Study }\end{array}$ & 1.0 & $1.48(1.06-2.07)$ & $1.06(0.75-1.50)$ & $1.28(0.90-1.83)$ & $1.20(0.76-1.91)$ & $1.79(0.93-3.45)$ & $0.98(0.11-8.83)$ & .27 \\
\hline New York State Cohort & 1.0 & $0.89(0.67-1.19)$ & $0.76(0.53-1.09)$ & $0.93(0.63-1.38)$ & $0.69(0.39-1.21)$ & $1.28(0.63-2.59)$ & $4.16(0.71-24.39)$ & .53 \\
\hline Nurses' Health Study (a) & 1.0 & $1.00(0.80-1.25)$ & $0.90(0.74-1.09)$ & $1.12(0.93-1.35)$ & $1.34(1.07-1.68)$ & $1.29(0.95-1.76)$ & $0.94(0.44-2.01)$ & .02 \\
\hline Nurses' Health Study $(b)$ & 1.0 & $1.07(0.83-1.38)$ & $0.97(0.79-1.19)$ & $1.01(0.81-1.25)$ & $0.95(0.71-1.26)$ & $1.20(0.85-1.70)$ & $1.64(0.78-3.43)$ & .23 \\
\hline $\begin{array}{l}\text { Sweden Mammography } \\
\text { Cohort }\end{array}$ & 1.0 & $1.10(0.87-1.39)$ & $1.19(0.97-1.46)$ & $1.13(0.84-1.52)$ & $1.03(0.36-2.95)$ & NA§ & NA§ & .23 \\
\hline Pooled & 1.0 & $1.07(0.96-1.19)$ & $0.99(0.90-1.10)$ & $1.06(0.96-1.17)$ & $1.16(0.98-1.38)$ & $1.41(1.18-1.69)$ & $1.31(0.86-1.98)$ & $<.001$ \\
\hline
\end{tabular}

*Multivariate relative risks were adjusted for age at menarche $(\leq 11,12,13,14$, or $\geq 15 y)$, parity $(0,1-2$, or $\geq 3)$, age at birth of first child $(\leq 20,21-25,26-30$, or $>30 \mathrm{y})$, menopause status at diagnosis (premenopausal, postmenopausal, or uncertain), postmenopausal hormone use (ever or never), oral contraceptive use (ever or never), history of benign breast disease (no or yes), maternal history of breast cancer (no or yes), history of breast cancer in a sister (no, yes, or no sisters), smoking status (ever or never), education ( $<$ high-school graduation, high-school graduation, or $>$ high-school graduation), body mass index (weight in kilograms divided by square of height in meters; $\leq 21,>21-23$, $>23-25,>25-29$, or $\left.>29 \mathrm{~kg} / \mathrm{m}^{2}\right)$, height $(<1.60,1.60$ to $<1.64,1.64$ to $<1.68$, or $\geq 1.68 \mathrm{~m}$ ), fat intake (quintiles), fiber intake (quintiles), and energy intake (continuous). tIn the United States, the mean alcohol intake is $13.2 \mathrm{~g}$ for a bottle or can of beer, $10.8 \mathrm{~g}$ for a glass of wine, and $15.1 \mathrm{~g}$ for a shot of liquor.

$\ddagger$ Numbers given in parentheses are the total numbers of cases in each category.

$\S N A$ indicates not applicable. Maximum alcohol consumption in Sweden was $31.3 \mathrm{~g} / \mathrm{d}$; thus, we could not calculate a relative risk for the 30 to $<60-$ and $\geq 60-\mathrm{g} / \mathrm{d}$ categories.

study-specific tests for interaction were calculated from the likelihood ratio test comparing models with and without the interaction terms. The pooled $P$ value for interaction was obtained using squared Wald statistics by pooling the study-specific interaction coefficients and dividing by the square of the SE of the pooled interaction term.

\section{RESULTS}

Among the cohorts, $22.5 \%$ to $55.3 \%$ of the controls were nondrinkers (Table 1). Mean intakes among controls who were drinkers ranged from 3.22 to $12.58 \mathrm{~g} / \mathrm{d}$ across studies. Alcohol consumption was positively associated with the risk of invasive breast cancer. Women who consumed, on average, 30 to less than $60 \mathrm{~g} / \mathrm{d}$ of alcohol (about 2-5 drinks per day) had a relative risk of 1.41 (95\% CI, 1.18-1.69; 194 breast cancer cases) compared with nondrinkers (Table 2). The association was slightly weaker for women who consumed $60 \mathrm{~g} / \mathrm{d}$ or more of alcohol $(\geq 4$ drinks per day) compared with nondrinkers (relative risk, 1.31; 95\% CI, 0.86-1.98; 30 breast cancer cases). Results of the tests for heterogeneity between studies were not statistically significant in any of the consumption categories, even though the patterns of risk differed somewhat across the studies. The pooled relative risks also were not materially different from the relative risks obtained when the studies were combined into 1 data set (data not shown).

Both the nonparametric regression curve (Figure) and test for linearity $(P=1.0$; null hypothesis, the association is linear) indicated that the association between alcohol and breast cancer was linear for alcohol intakes less than $60 \mathrm{~g} / \mathrm{d}$. Although the curve flattened out at in-

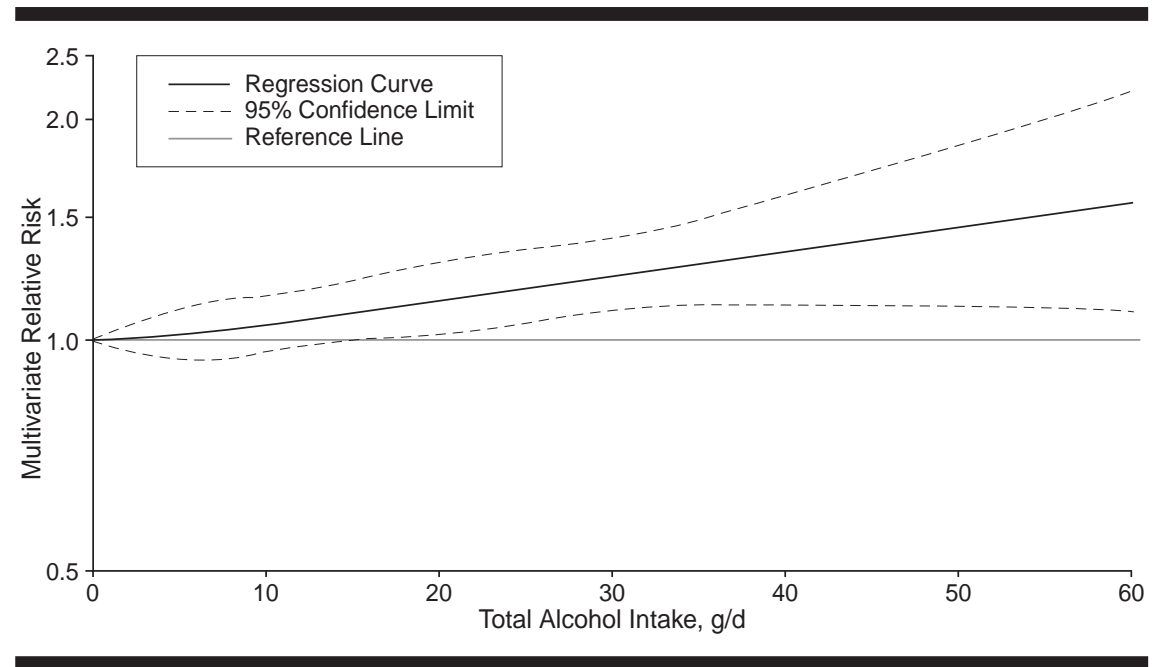

Nonparametric regression curve for the relationship between total alcohol intake and breast cancer.

takes above $60 \mathrm{~g} / \mathrm{d}$, the test for linearity did not provide evidence for a departure from linearity $(P=.33)$; however, the CIs became very wide because of sparse data.

Because the assumption of linearity was reasonable, we analyzed alcohol intake as a continuous variable. In analyses restricted to women with alcohol intakes less than $60 \mathrm{~g} / \mathrm{d}$ ( $>99 \%$ of the women), breast cancer risk increased by $3 \%$ to $16 \%$ for an increase in alcohol intake of $10 \mathrm{~g} / \mathrm{d}$ (approximately 0.75-1 drink per day) across the individual studies. In the pooled analyses, breast cancer risk increased by $9 \%$ (95\% CI, 1.04-1.13) for a $10-\mathrm{g} / \mathrm{d}$ increase in alcohol intake $(P$ for heterogeneity among studies, .71). Correction for measurement error in alcohol intake did not affect the association (pooled multivariate relative risk corrected for measurement error, 1.08 for a $10-\mathrm{g} / \mathrm{d}$ increase in total alcohol intake;
95\% CI, 1.01-1.16). The association was slightly weaker when participants with intakes of $60 \mathrm{~g} / \mathrm{d}$ or greater were included in the analysis (pooled multivariate relative risk corrected for measurement error, 1.07; 95\% CI, 1.01-1.14). For both the categorical and continuous analyses, similar results were obtained when cases diagnosed within the first 1 , 2,3 , and 4 years of follow-up were excluded (data not shown).

Continuous estimates of alcohol intakes from beer, wine, and liquor were each positively associated with breast cancer risk in the multivariate analyses. Breast cancer risk increased by $11 \%$ (95\% CI, 1.04-1.19), 5\% (95\% CI, 0.981.12 ), and $5 \%$ (95\% CI, 1.01-1.10) for daily increases of $10 \mathrm{~g} / \mathrm{d}$ of alcohol from beer, wine, and liquor, respectively, when all 3 beverages were included in the same model. As in the analyses for total alcohol intake, slightly stronger relative 
Table 3.-Pooled Multivariate Relative Risks* for a 10-g/d Increment in Total Alcohol Intake by Levels of Other Breast Cancer Risk Factors

\begin{tabular}{|c|c|c|}
\hline Factor & $\begin{array}{c}\text { Relative Risk } \\
\text { (95\% Confidence Interval) }\end{array}$ & $\begin{array}{c}P \text { for } \\
\text { Interaction }\end{array}$ \\
\hline \multicolumn{3}{|l|}{ Menopausal status $\dagger$} \\
\hline Premenopausal & $1.00(0.87-1.15)$ & \multirow{2}{*}{.49} \\
\hline Postmenopausal & $1.05(1.01-1.10)$ & \\
\hline \multicolumn{3}{|c|}{ Maternal history of breast cancerł } \\
\hline No & $1.07(1.03-1.11)$ & \multirow{2}{*}{.22} \\
\hline Yes & $0.98(0.85-1.14)-$ & \\
\hline \multicolumn{3}{|c|}{ History of breast cancer in sisterł } \\
\hline No & $1.08(1.04-1.12)$ & \multirow{2}{*}{.74} \\
\hline Yes & $1.11(0.96-1.29)$ & \\
\hline \multicolumn{3}{|c|}{ Hormone replacement therapy use } \\
\hline Never & $1.09(1.03-1.14)$ & \multirow{3}{*}{.80} \\
\hline Past & $1.09(1.00-1.18)$ & \\
\hline Current & $1.06(0.98-1.16)$ & \\
\hline \multicolumn{3}{|l|}{ Body mass index, $\mathrm{kg} / \mathrm{m}^{2}$} \\
\hline$\leq 21$ & $1.02(0.91-1.13)$ & \multirow{5}{*}{.31} \\
\hline$>21-23$ & $1.07(1.00-1.14)$ & \\
\hline$>23-25$ & $1.11(1.04-1.18)$ & \\
\hline$>25-29$ & $1.04(0.97-1.11)$ & \\
\hline$>29$ & $1.12(1.02-1.22)$ & \\
\hline
\end{tabular}

*The relative risks were adjusted for the covariates listed in the first footnote to Table 2.

†The lowa Women's Health Study, Netherlands Cohort Study, and New York State Cohort enrolled postmenopausal women only and were not included in this analysis.

$\ddagger$ The New York State Cohort was not included in this analysis.

risks were obtained when participants with alcohol intakes of $60 \mathrm{~g} / \mathrm{d}$ or greater were excluded; relative risks for a $10-\mathrm{g} / \mathrm{d}$ increase in alcohol intake from beer, wine, and liquor were 1.14 (95\% CI, 1.04$1.24), 1.08$ (95\% CI, $1.00-1.16)$, and 1.08 (95\% CI, 1.02-1.14), respectively. The beverage-specific estimates were not statistically different from one another.

We evaluated whether menopausal status at diagnosis modified the alcohol and breast cancer association (Table 3). For this comparison, only the 4 studies with both premenopausal and postmenopausal breast cancer cases were included. Among premenopausal women $(n=717$ breast cancer cases), heterogeneity across the individual studies was evident ( $P$ for heterogeneity, .03). Study-specific multivariate relative risks for a $10-\mathrm{g} / \mathrm{d}$ increase in alcohol intake ranged from 0.45 (95\% CI, 0.19-1.07) for the Sweden Mammography Cohort to 1.09 (95\% CI, 0.94-1.26) for the Canadian National Breast Screening Study. The pooled multivariate relative risk was $1.00(95 \% \mathrm{CI}$, 0.87-1.15). For postmenopausal women $(n=3163$ breast cancer cases), there was no evidence of heterogeneity across studies ( $P$ for heterogeneity, .96). The pooled relative risk for postmenopausal breast cancer for all studies was 1.08 (95\% CI, $1.04-1.12$ ) for a $10-\mathrm{g} / \mathrm{d}$ increase in alcohol consumption. For the 4 studies that included both postmenopausal and premenopausal women, the corresponding relative risk of postmenopausal breast cancer was 1.05 (95\% CI, 1.01-1.10). The result of a statistical test for an interaction by menopausal status was not significant $(P=.49)$.
For each of the other factors evaluated as potential effect modifiers, alcohol consumption was positively associated with the risk of breast cancer in each category except for a positive maternal history of breast cancer (Table 3). No statistically significant pooled interactions were observed. The $P$ values for interaction for other factors that were evaluated but not included in Table 3 were .52 for age at menarche, .45 for parity, .48 for age at first birth, .81 for history of benign breast disease, .12 for oral contraceptive use, .33 for education, .70 for height, .25 for fiber intake, .18 for fat intake, and .31 for smoking.

\section{COMMENT}

These analyses indicate that alcohol consumption and the risk of invasive breast cancer are positively associated in women. Women consuming 30 to less than $60 \mathrm{~g} / \mathrm{d}$ of alcohol (approximately 2.3 4.5 bottles of beer,2.8-5.6 glasses of wine, or 2.0-4.0 shots of liquor) had a $41 \%$ higher risk of invasive breast cancer than nondrinkers. Women consuming 60 $\mathrm{g} / \mathrm{d}$ or more of alcohol had a $31 \%$ higher risk of invasive breast cancer. This attenuation of the alcohol and breast cancer association at intakes of at least 60 $\mathrm{g} / \mathrm{d}$ may be due to increased measuretion at high intakes, lack of precision resulting from the very small sample size in the highest consumption category (30 cases, 194 controls), or a real physiologic has been reported to plateau at very high alcohol intakes in some other studies evaluating breast cancer incidence..$^{29-32}$ ment error in reported alcohol consumpphenomenon, since breast cancer risk
Moreover, a similar pattern was observed in the Cancer Prevention Study II, which examined breast cancer mortality. Compared with nondrinkers, women who consumed 2 to 3 drinks per day had a $50 \%$ higher risk of breast cancer mortality (95\% CI, 1.2-1.9), but women who consumed at least 4 drinks a day showed no increase in breast cancer mortality (relative risk, 1.0; 95\% CI, $0.7-1.4) .^{33}$ In our continuous analyses, breast cancer risk was significantly elevated by $9 \%$ for each $10-\mathrm{g} / \mathrm{d}$ increase in alcohol intake for intakes up to $60 \mathrm{~g} / \mathrm{d}$ (reported by more than $99 \%$ of the participants). When participants with intakes of $60 \mathrm{~g} / \mathrm{d}$ or greater were included in the analysis, the corresponding relative risk was somewhat attenuated due to the influence of the extreme intake values. The source of the alcohol did not strongly influence the risk estimates. As in most studies, ${ }^{2}$ menopausal status did not significantly modify the relationship between alcohol consumption and breast cancer. Although we found little evidence of a positive association among premenopausal women, the CIs were wide and included the association found among postmenopausal women. The alcohol and breast cancer association was not modified by other factors, suggesting that the increased risk associated with increasing alcohol consumption applies to most women.

Many studies have reported associations for alcohol consumption and breast cancer in women. Summarization of these studies is difficult because of the variety of analyses conducted. Studies have compared the number of drinks consumed, the grams of alcohol consumed, and whether individuals consumed any alcohol. Nevertheless, most ${ }^{2,6,14,31,32,34-42}$ but not all ${ }^{2,15,43-49}$ studies have found an increase in breast cancer risk with high alcohol consumption. Generally, the relative risks have been less than 2.0 for the highest vs the lowest consumers of alcohol. Several of the positive associations ${ }^{2,6,31,34-42}$ but few of the inverse associations ${ }^{2,48}$ have been statistically significant. One possible explanation for the substantial number of positive but nonsignificant findings may be that individual studies have had limited power to detect associations of the magnitude observed for alcohol and breast cancer. Pooling the data from multiple studies, as in the analyses presented here, enhances the power to detect associations of smaller magnitude.

A recent meta-analysis also found that overall breast cancer risk was elevated by $9 \%$ for a $10-\mathrm{g} / \mathrm{d}$ increase in total alcohol intake. ${ }^{2}$ To calculate this statistic, study-specific published results were reexpressed as the slopes of dose-response 
curves after standardized intake definitions were applied to each consumption category. Our pooled results support the linearity of the assumption at intakes less than $60 \mathrm{~g} / \mathrm{d}$ and are similar to the findings of the meta-analysis, even though 3 additional cohort studies were included in our analysis, and for 2 of the 3 studies included in both analyses, more than 1400 additional incident breast cancer cases were included in our pooled analyses.

Recently, progress has been made in understanding potential biological mechanisms by which alcohol may increase breast cancer risk. Several studies $^{50-52}$ have shown positive correlations between alcohol intake and plasma or urinary estrogen levels; however, other studies have found no association. ${ }^{53-57}$ Moreover, some studies have found that women with alcoholism have higher estrogen levels than moderate alcohol consumers ${ }^{58,59}$ and nondrinkers ${ }^{60}$ although 1 study found no difference between alcoholic women and moderate alcohol consumers. ${ }^{61}$ Several intervention studies have found that estradiol levels increased significantly when alcohol but not placebo was administered to premenopausal women ${ }^{62-64}$ and postmenopausal women ${ }^{65}$ who used estrogen replacement therapy. In addition, in a crossover feeding study of premenopausal women, significantly higher urinary but not plasma estrogen levels were observed in the luteal phase of the menstrual cycle during the alcohol-containing diet period compared with the alcohol-free diet period. ${ }^{66}$ The increased estrogen level in women consuming alcohol is hypothesized to be due either to a decrease in the metabolic clearance of estrogens or to increased secretion. ${ }^{67} \mathrm{Al}-$ cohol also may affect breast cancer risk by acting as a cocarcinogen, improving the permeability of membranes to carcinogens, inhibiting the detoxification of carcinogens, and activating procarcinogens. ${ }^{68}$

There are several limitations of this pooled analysis. Only information on current alcohol consumption at baseline was available across all studies. As a result, the reference group of nondrinkers may include former drinkers. Some studies have shown that former drinkers have an increased risk of breast cancer compared with never drinkers. ${ }^{69-71}$ Thus, our results for current alcohol consumption may be somewhat attenuated. In addition, since only recent alcohol consumption was measured, lifetime alcohol consumption and consumption during early adulthood could not be examined. Alcohol consumption may be underreported, thereby biasing estimates of dose-response relationships toward the null.
However, validation studies of the food frequency questionnaires used in each of these studies have shown that alcohol intake was measured with high validity. ${ }^{12,23,24,72}$ Moreover, risk estimates were only slightly changed in analyses that corrected for measurement error in the food frequency questionnaire.

This study provides further evidence that alcohol consumption increases breast cancer risk among women. The approximately $30 \%$ to $40 \%$ higher risk in individuals consuming at least $30 \mathrm{~g} / \mathrm{d}$ of alcohol vs nondrinkers is similar to or slightly stronger than associations observed for several reproductive factors and a positive family history. For example, in this data set, breast cancer risk was $25 \%$ higher in women whose age at menarche was 12 years or younger vs 15 years or older and was 50\% higher for women with a history of breast cancer in their mother compared with women who had no family history. ${ }^{5}$ However, unlike these risk factors, alcohol intake is a potentially modifiable behavior. Future research should focus on the effects of drinking patterns, the influence of early drinking on risks associated with drinking at later ages, the potential effects of high alcohol consumption, and the potential mechanisms by which alcohol may affect breast cancer risk. Since moderate alcohol consumption is associated with reduced risks of cardiovascular disease and overall mortality among women, ${ }^{33,73,74}$ the risk-benefit ratio of alcohol consumption is complex. However, other modifiable risk factors exist that reduce the risk of heart disease, such as moderate exercise, avoiding smoking, and avoiding obesity. ${ }^{75}$ Ultimately, analyses simultaneously considering cancer, cardiovascular disease, and other end points, such as traffic accidents and domestic trauma, are required to define the costs and benefits of alcohol consumption. Meanwhile, reduction of regular alcohol consumption in women is likely to reduce breast cancer risk.

This study was supported by research grants CA55075 and CA50597 from the National Institutes of Health, Bethesda, Md; by a grant from the Wallace Genetic Foundation Inc, Washington, DC (Dr Smith-Warner); and by a Faculty Research Award (FRA-455) from the American Cancer Society, Washington, DC (Dr Hunter).

The authors thank Tim Baum and Karen Corsano for computer support.

\section{References}

1. Kelsey J, Horn-Ross PL. Breast cancer: magnitude of the problem and descriptive epidemiology. Epidemiol Rev. 1993;15:7-16.

2. Longnecker MP. Alcoholic beverage consumption in relation to risk of breast cancer: meta-analysis and review. Cancer Causes Control. 1994;5:73-82.

3. Rosenberg L, Metzger LS, Palmer JR. Alcohol consumption and risk of breast cancer: a review of the epidemiologic evidence. Epidemiol Rev. 1993; 15:133-144.
4. Hunter DJ, Spiegelman D, Adami H-O, et al. Cohort studies of fat intake and the risk of breast cancer: a pooled analysis. $N$ Engl $J$ Med. 1996;334:356361.

5. Hunter DJ, Spiegelman D, Adami H-O, etal. Nondietary factors as risk factors for breast cancer, and as effect modifiers of the association of fat intake and risk of breast cancer. Cancer Causes Control. 1997 ; 8:49-56.

6. van den Brandt PA, Goldbohm RA, van't Veer P. Alcohol and breast cancer: results from the Netherlands Cohort Study. Am J Epidemiol. 1995;141: 907-915.

7. Holmberg L, Ohlander EM, Byers T, et al. Diet and breast cancer risk: results from a populationbased, case-control study in Sweden. Arch Intern Med. 1994;154:1805-1811.

8. Friedenreich CM, Howe GR, Miller AB, Jain MG. A cohort study of alcohol consumption and risk of breast cancer. Am J Epidemiol. 1993;137:512-520. 9. Gapstur SM, Potter JD, Sellers TA, Folsom AR. Increased risk of breast cancer with alcohol consumption in postmenopausal women. Am J Epidemiol. 1992;136:1221-1231.

10. Graham S, Zielezny M, Marshall J, et al. Diet in the epidemiology of postmenopausal breast cancer in the New York State Cohort. Am J Epidemiol. 1992;136:1327-1337.

11. Mills PK, Beeson WL, Phillips RL, Fraser GE. Dietary habits and breast cancer incidence among Seventh-Day Adventists. Cancer. 1989;64:582-590. 12. Willett WC, Stampfer MJ, Colditz GA, Rosner BA, Hennekens CH, Speizer FE. Moderate alcohol consumption and the risk of breast cancer. $N$ Engl $J$ Med. 1987;316:1174-1180.

13. Hunter DJ, Willett WC. Diet, body size, and breast cancer. Epidemiol Rev. 1993;15:110-132.

14. Holmberg L, Baron JA, Byers T, et al. Alcohol intake and breast cancer risk: effect of exposure from 15 years of age. Cancer Epidemiol Biomarkers Prev. 1995;4:843-847.

15. Schatzkin A, Carter CL, Green SB, et al. Is alcohol consumption related to breast cancer? results from the Framingham Heart Study. J Natl Cancer Inst. 1989;81:31-35.

16. Byers T, Graham S, Rzepka T, Marshall J. Lactation and breast cancer: evidence for a negative association in premenopausal women. Am J Epidemiol. 1985;121:664-674.

17. Kaplan E, Meier P. Nonparametric estimation from incomplete observations. J Am Stat Assoc. 1958;8:699-712

18. Prentice RL. A case-cohort design for epidemiologic cohort studies and disease prevention trials. Biometrika. 1986;73:1-11.

19. SAS/STAT Software: The PHREG Procedure: Preliminary Documentation. Cary, NC: SAS Institute Inc; 1991.

20. EPICURE User's Guide: The PEANUTS Program. Seattle, Wash: Hirosoft Int Corp; 1993.

21. DerSimonian R, Laird N. Meta-analysis in clinical trials. Control Clin Trials. 1986;7:177-188.

22. Jain MG, Harrison L, Howe GR, Miller AB. Evaluation of a self-administered dietary questionnaire for use in a cohort study. Am J Clin Nutr. 1982;36:931-935.

23. Munger RG, Folsom AR, Kushi LH, Kaye SA, Sellers TA. Dietary assessment of older Iowa women with a food frequency questionnaire: nutrient intake, reproducibility, and comparison with 24-hour dietary recall interviews. Am J Epidemiol. 1992; 136:192-200.

24. Goldbohm RA, van den Brandt PA, Brants HAM, et al. Validation of a dietary questionnaire used in a large-scale prospective cohort study on diet and cancer. Eur J Clin Nutr. 1994;48:253-265. 25. Feskanich D, Marshall J, Rimm EB, Litin LB, Willett WC. Simulated validation of a brief food frequency questionnaire. Ann Epidemiol. 1994;4:181187.

26. Willett WC, Sampson L, Stampfer MJ, et al. Reproducibility and validity of a semiquantitative food frequency questionnaire. Am J Epidemiol. 1985;122:51-65.

27. Durrleman S, Simon R. Flexible regression 
models with cubic splines. Stat Med. 1989;8:551-561. 28. Smith PL. Splines as a useful and convenient statistical tool. Am Stat. 1979;33:57-62.

29. Hiatt RA, Bawol RD. Alcoholic beverage consumption and breast cancer incidence. Am J Epidemiol. 1984;120:676-683.

30. Le MG, Hill C, Kramar A, Flamant R. Alcoholic beverage consumption and breast cancer in a French case-control study. Am J Epidemiol. 1984;120:350357.

31. Longnecker MP, Newcomb PA, Mittendorf R, et al. Risk of breast cancer in relation to lifetime alcohol consumption. J Natl Cancer Inst. 1995;87: 923-929.

32. Longnecker MP, Paganini-Hill A, Ross RK. Lifetime alcohol consumption and breast cancer risk among postmenopausal women in Los Angeles. Cancer Epidemiol Biomarkers Prev. 1995;4:721-725.

33. Thun MJ, Peto R, Lopez AD, et al. Alcohol consumption and mortality among middle-aged and elderly U.S. adults. $N$ Engl $J$ Med. 1997;337:17051714.

34. Levi F, La Vecchia C, Gulie C, Negri E. Dietary factors and breast cancer risk in Vaud, Switzerland. Nutr Cancer. 1993;19:327-335.

35. Martin-Moreno JM, Boyle P, Gorgojo L, et al. Alcoholic beverage consumption and risk of breast cancer in Spain. Cancer Causes Control. 1993;4:345353.

36. Katsouyanni K, Trichopoulou A, Stuver S, et al. Ethanol and breast cancer: an association that may be both confounded and causal. Int J Cancer. 1994; 58:356-361.

37. Landa M-C, Frago N, Tres A. Diet and the risk of breast cancer in Spain. Eur J Cancer Prev. 1994 3:313-320.

38. Levi F, Pasche C, Lucchini F, La Vecchia C. Alcohol and breast cancer in the Swiss Canton of Vaud. Eur J Cancer. 1996;32A:2108-2113.

39. Weiss HA, Brinton LA, Brogan D, et al. Epidemiology of in situ and invasive breast cancer in women aged under 45. Br J Cancer. 1996;73:1298-1305. 40. Swanson CA, Coates RJ, Malone KE, et al. Alcohol consumption and breast cancer risk among women under age 45 years. Epidemiology. 1997;8: 231-237.

41. VielJ-F, PerarnauJ-M, Challier B, Faivre-Nappez I. Alcoholic calories, red wine consumption and breast cancer among premenopausal women. Eur . Epidemiol. 1997;13:639-643.

42. Bowlin SJ, Leske MC, Varma A, Nasca P, Weinstein A, Caplan L. Breast cancer risk and alcoho consumption: results from a large case-control study. Int J Epidemiol. 1997;26:915-923.

43. Katsouyanni K, Trichopoulos D, Boyle P, et al. Diet and breast cancer: a case-control study in Greece. Int J Cancer. 1986;38:815-820.

44. Adami H-O, Lund E, Bergström R, Meirik O. Cigarette smoking, alcohol consumption and risk of breast cancer in young women. Br J Cancer. 1988; $58: 832-837$.
45. Ewertz M. Alcohol consumption and breast cancer risk in Denmark. Cancer Causes Control. 1991; 2:247-252.

46. Kato I, Miura S, Kasumi F, et al. A case-control study of breast cancer among Japanese women: with special reference to family history and reproductive and dietary factors. Breast Cancer Res Treat. 1992; 24:51-59.

47. Rohan TE, Hiller JE, McMichael AJ. Dietary factors and survival from breast cancer. Nutr Cancer. 1993;20:167-177.

48. Smith SJ, Deacon JM, Chilvers CED, members of the UK National Case-Control Study Group. Alcohol, smoking, passive smoking and caffeine in relation to breast cancer risk in young women. $\mathrm{Br} J$ Cancer. 1994;70:112-119.

49. Freudenheim JL, Marshall JR, Graham S, et al. Lifetime alcohol consumption and risk of breast cancer. Nutr Cancer. 1995;23:1-11.

50. Katsouyanni K, Boyle P, Trichopoulos D. Diet and urine estrogens among postmenopausal women. Oncology. 1991;48:490-494.

51. Hankinson SE, Willett WC, Manson JE, et al. Alcohol, height, and adiposity in relation to estrogen and prolactin levels in postmenopausal women. $J$ Natl Cancer Inst. 1995;87:1297-1302.

52. Gavaler JS, van Thiel DH. The association between moderate alcoholic beverage consumption and serum estradiol and testosterone levels in normal postmenopausal women: relationship to the literature. Alcohol Clin Exp Res. 1992;16:87-92.

53. Cauley JA, Gutai JP, Kuller LH, LeDonne D, PowellJG. The epidemiology of serum sex hormones in postmenopausal women. Am J Epidemiol. 1989; 129:1120-1131.

54. London S, Willett W, Longcope C, McKinlay S. Alcohol and other dietary factors in relation to serum hormone concentrations in women at climacteric. Am J Clin Nutr. 1991;53:166-171.

55. Newcomb PA, Klein R, Klein BEK, et al. Association of dietary and life-style factors with sex hormones in postmenopausal women. Epidemiology. $1995 ; 6: 318-321$.

56. Trichopoulos D, Brown J, MacMahon B. Urine estrogens and breast cancer risk factors among postmenopausal women. Int $J$ Cancer. 1987;40:721-725. 57. Dorgan JF, Reichman ME, Judd JT, et al. The relation of reported alcohol ingestion to plasma levels of estrogens and androgens in premenopausal women (Maryland, United States). Cancer Causes Control. 1994:5:53-60.

58. Becker U, Gluud C, Farholt S, et al. Menopausal age and sex hormones in postmenopausal women with alcoholic and non-alcoholic liver disease. J Hepatol. 1991;13:25-32.

59. Pettersson P, Ellsinger B-M, Sjöberg C, Björntorp P. Fat distribution and steroid hormones in women with alcohol abuse. J Intern Med. 1990;228: 311-316.

60. Gavaler JS, van Thiel DH. Hormonal status of postmenopausal women with alcohol-induced cir- rhosis: further findings and a review of the literature. Hepatology. 1992;16:312-319.

61. Välimäki MJ, Laitinen K, Tiitinen A, Steman U-H, Ylöstalo P. Gonadal function and morphology in non-cirrhotic female alcoholics: a controlled study with hormone measurements and ultrasonography. Acta Obstet Gynecol Scand. 1995;74:462-466.

62. Mendelson JH, Lukas SE, Mello NK, Amass L, Ellingboe J, Skupny A. Acute alcohol effects on plasma estradiol levels in women. Psychopharmacology. 1988;94:464-467.

63. Mendelson JH, Mello NK, Cristofaro P, et al Alcohol effects on naloxone-stimulated luteinizing hormone, prolactin and estradiol in women. J Stud Alcohol. 1987;48:287-294.

64. MendelsonJH, Mello NK, Teoh SK, EllingboeJ. Alcohol effects on luteinizing hormone releasing hormone-stimulated anterior pituitary and gonadal hormones in women. J Pharmacol Exp Ther. 1989; 250:902-909.

65. Ginsburg ES, Mello NK, Mendelson JH, et al. Effects of alcohol ingestion on estrogens in postmenopausal women. JAMA. 1996;276:17471751 .

66. Reichman ME, Judd JT, Longcope C, et al. Effects of alcohol consumption on plasma and urinary hormone concentrations in premenopausal women. $J$ Natl Cancer Inst. 1993;85:722-727.

67. Ginsburg ES, Walsh BW, Shea BF, Gao X, Gleason RE, Barbieri RL. The effects of ethanol on the clearance of estradiol in postmenopausal women. Fertil Steril. 1995;63:1227-1230.

68. Garro AJ, Lieber CS. Alcohol and cancer. Annu Rev Pharmacol Toxicol. 1990;30:219-249.

69. Rosenberg L, Slone D, Shapiro S, et al. Breast cancer and alcoholic-beverage consumption. Lancet. 1982;1:267-271.

70. O'Connell DL, Hulka BS, Chambless LE, Wilkinson WE, Deubner DC. Cigarette smoking, alcohol consumption, and breast cancer risk. J Natl Cancer Inst. 1987;78:229-234.

71. Hiatt RA, Klatsky AL, Armstrong MA. Alcohol consumption and the risk of breast cancer in a prepaid health plan. Cancer Res. 1988:48:2284-2287.

72. Goldbohm RA, van't Veer P, van den Brandt $\mathrm{PA}$, et al. Reproducibility of a food frequency questionnaire and stability of dietary habits determined from 5 annually repeated measurements. Eur JClin Nutr. 1995;49:420-429.

73. Stampfer MJ, Colditz GA, Willett WC, Speizer $\mathrm{FE}$, Hennekens $\mathrm{CH}$. A prospective study of moderate alcohol consumption and the risk of coronary disease and stroke in women. $N$ Engl $J$ Med. 1988; 319:267-273.

74. Fuchs CS, Stampfer MJ, Colditz GA, et al. Alcohol consumption and mortality among women. N Engl J Med. 1995;332:1245-1250.

75. Rich-EdwardsJW, MansonJE,Hennekens CH, Buring JE. The primary prevention of coronary heart disease in women. $N$ Engl J Med. 1995;332: $1758-1766$ 